\title{
The cold frontal depression that affected the area of Cyprus between 28 and 29 January 2008
}

\author{
K. Nicolaides, A. Orphanou, K. Savvidou, S. Michaelides, and M. Tsitouri \\ Meteorological Service, Nicosia, Cyprus \\ Received: 16 June 2009 - Revised: 14 June 2010 - Accepted: 26 August 2010 - Published: 15 September 2010
}

\begin{abstract}
The baroclinic depression that affected the area of Cyprus during the cold period, between 28 and 29 January 2008 was thoroughly studied and is presented in the present paper. A small perturbation on a northwesterly flow to the north of Cyprus has initiated the generation of the depression and in $24 \mathrm{~h}$ this developed into a deep baroclinic system. This depression was associated with intense weather phenomena, such as heavy thunderstorms with hail and near gale force winds. Strong cold advection resulted in a significant temperature decrease; precipitation even in lower altitudes was in the form of snow, while the accumulated rainfall corresponded to the $25 \%$ of the monthly normal. January 2008 is considered as a dry month, despite the fact that, on the average, January is considered as the wettest month of the year. In this study, the evolution and development of the depression was investigated from synoptic, dynamic, energetic and thermodynamic perspectives, in order to enhance our knowledge on the life cycle and behaviour of similar depressions over the area with extreme characteristics.
\end{abstract}

\section{Introduction}

The climatic characteristics of the area of the eastern Mediterranean are related to the medium and upper tropospheric circulation (Radinovic, 1987; Jacobeit, 1987); the prevailing westerly air flow is a result of the combination of the zone of subtropical highs to the south and the midlatitude zone of frequent passage of lows, just to the north. During the winter, the area of the eastern Mediterranean is under the influence of the southwestern edge of the Siberian anticyclone resulting in the observed relatively high surface pressure fields. The area is also affected by depressions with intense baroclinic characteristics (El-Fandy, 1946; Kallos and Metaxas, 1980; Maheras et al., 2002). These depressions invade the area mostly from the west, while only a small number of them approach from the north direction (Michaelides et al., 2004; Nicolaides et al., 2004; Nicolaides, 2005). The present study refers to the investigation of the synoptic, dynamic, thermodynamic and energetic characteristics of the cold frontal depression which entered into the eastern Mediterranean from the north and affected the area of Cyprus during the period from the 28 to 29 January 2008.

It has long been realized, but only recently documented, that the area of Cyprus is considered as a region with relatively frequent cyclogenesis (Maheras et al., 2001). The contribution of various cyclogenetic factors in the Mediterranean basin has been emphasized by several researchers; primary of such factors is the orographic forcing (Tafferner and Egger, 1990; Stein and Alpert, 1993). During the winter, in the eastern Mediterranean, the relatively warmer sea acts as a source of moisture and latent and sensible heat, as shown by ShayEl and Alpert (1991) and Stein and Alpert (1993). Cyprus' area has been recognized as the second most favorable region for cyclogenesis in the Mediterranean, after Genoa's Gulf.

The aim of the present research is to study the evolution and development of the depression from different perspectives, in order to enhance our knowledge on the life cycle and behaviour of depressions over the area with extreme characteristics. The data and methodology adopted are discussed in Sect. 2. The results are presented in Sect. 3: in Sect. 3.1 a brief synoptic description of the event if given; Sect. 3.2 comprises the dynamic study, while the thermodynamic analysis is presented in Sect. 3.3; the results of the energetic analysis are presented in Sect. 3.4. Concluding remarks are made in Sect. 4. 


\section{Data and methodology}

In order to study the characteristics of the system in a spatial and temporal context, several dynamic, energetic and thermodynamic parameters were calculated for selected isobaric layers, for the period extending from 26 until 30 January 2008.

The studied dynamic parameters were the relative vorticity, the divergence of the horizontal wind vector; the vertical motion and the static instability (Nicolaides et al., 2004 for a comprehensive mathematical presentation). For the energetic study, the zonal components of the available potential and kinetic energies (ZAPE and ZKE, respectively), their eddy counterparts (EAPE and EKE, respectively), their conversions and boundary transfers were calculated (see Michaelides 1987 and 1992 for a thorough mathematical formulation and physical interpretation of the energetic components). For the needs of the thermodynamic analysis, several thermodynamic indices were examined, using local radiosonde data, namely those from Athalassa radiosonde station $\left(35^{\circ} 09^{\prime} \mathrm{N}, 33^{\circ} 24^{\prime} \mathrm{E}\right)$, located in the centre of the island. Radiosonde data are available only at 06:00 UTC and 12:00 UTC and these were used in order to reveal a possible temporal evolution of these indices. The definition and interpretation of the various thermodynamic parameters can be found online (http://www.crh.noaa.gov/lmk/soo/docu/ indices.php). The data used for the required mathematical calculations were deduced from the NCEP/NCAR global reanalyses for 00:00 UTC, with a grid dimension of $2.5^{\circ} \times 2.5^{\circ}$; the area of the calculations is bounded by meridians $20^{\circ} \mathrm{W}$ and $50^{\circ} \mathrm{E}$ and parallel circles $20^{\circ} \mathrm{N}$ and $65^{\circ} \mathrm{N}$. The resolution resulting from the grid distance is considered to be adequate for the synoptic-scale analysis carried out here; data at finer resolutions could be used, but they would not alter the basic characteristics of the distributions of the dynamic parameters at the scale considered. For the synoptic investigation, surface and upper air charts and surface observations from the archives of Cyprus Meteorological Service were also used, together with satellite images at different wavelengths.

\section{Results}

\subsection{Synoptic study}

At 00:00 UTC 28 January 2008, an extensive barometric low was affecting the eastern Europe, with Cyprus lying on its southern edge, having a mean sea level pressure (MSLP) value of $1014 \mathrm{hPa}$ (Fig. 1). The predominant airflow over Cyprus was from the west. A significant change was noted 24 h later (00:00 UTC 29 January 2008), when a deep and well marked barometric low formed in the eastern Mediterranean, being cut-off from the pre-existing broader cyclonic circulation (Fig. 2). The depression was covering the north

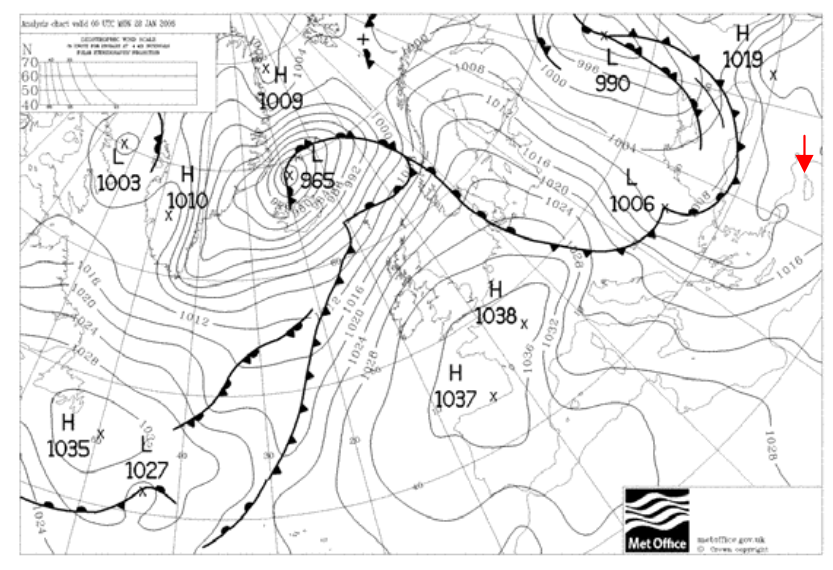

Fig. 1. Surface analysis chart for 00:00 UTC 28 January 2008 (UK, Met. Office). The red arrow points to Cyprus area.

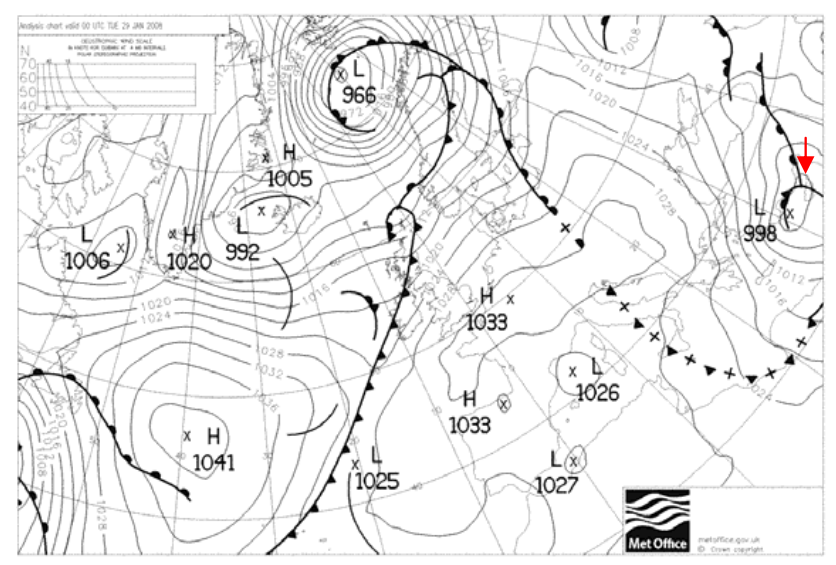

Fig. 2. Surface analysis chart for 00:00 UTC 29 January 2008 (UK, Met. Office). The red arrow points to Cyprus area.

part of the eastern Mediterranean basin and its lowest pressure was $998 \mathrm{hPa}$, just to the west of the island of Cyprus. This depression progressed eastwards and filled in the following $24 \mathrm{~h}$ period, while all associated phenomena ceased by 00:00 UTC 31 January.

During the studied period, the pressure decreased remarkably, reaching a rate of $5 \mathrm{hPa}$ per $3 \mathrm{~h}$. The continuous fall in pressure resulted in a strengthening of the gradient; westerlysouthwesterly winds reached mean speeds of $30 \mathrm{kt}$. Both stratiform cloud at all tropospheric levels and cumuliform cloud with bases at lower levels had increased in amount and the first rain and shower events began by 07:00 UTC, 28 January. Thunderstorm activity of moderate and heavy intensity and hail were reported after 12:00 UTC on the same day. The wind speed decreased after 18:00 UTC and precipitation was mostly in the form of rain or light showers after 22:00 UTC. The minimum MSLP reported over Cyprus was $998 \mathrm{hPa}$ and it has been recorded from 01:00 UTC until 04:00 UTC 29 January. Nevertheless, thunderstorm activity 


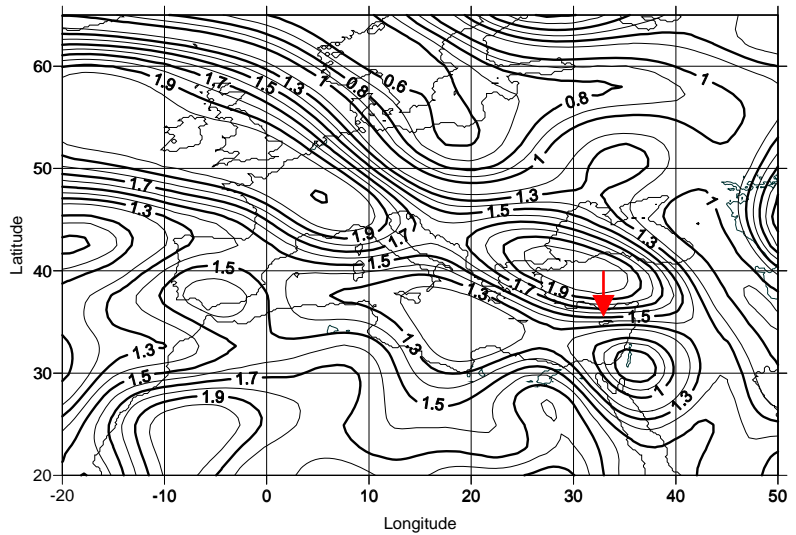

(a)

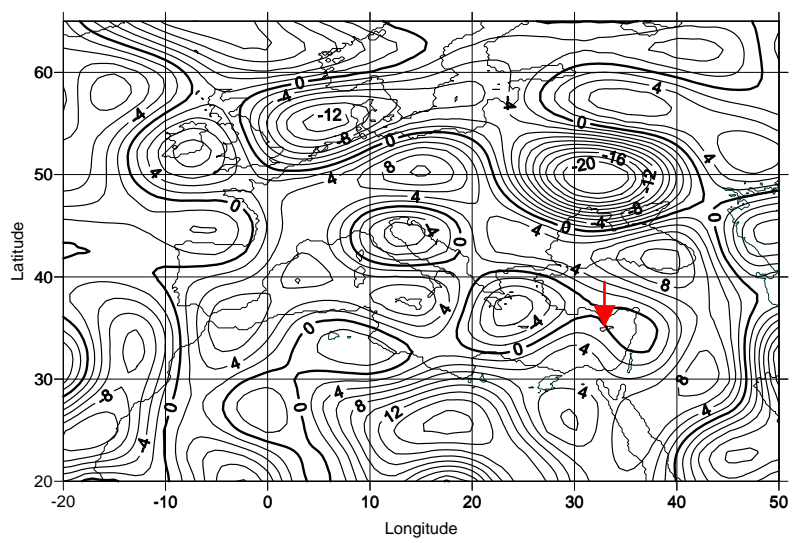

(b)

Fig. 3. (a) Static stability index (unit: $\mathrm{K}^{2} \mathrm{~s}^{-1}$ ); (b) Divergence of the horizontal wind vector (unit: $\times 10^{-6} \mathrm{~s}^{-1}$ ) at the isobaric layer of $850 \mathrm{hPa}$, at 00:00 UTC 27 January 2008. The red arrow point to Cyprus area.

was noted again at 06:00 UTC and lasted until 13:00 UTC 29 January. A northerly surface flow was established as from 11:00 UTC 29 January 2008, while the cloud bands began to move away or clear by 20:00 UTC.

\subsection{Dynamic study}

\subsubsection{January 2008}

At the lower troposphere, as represented by the isobaric level of $850 \mathrm{hPa}$, stable air (see Fig. 3, where high values of static stability index denote stable air, whereas lower values denote less stable air) covered the area of the Black Sea and Asia Minor (the static stability index obtains values of more than $2.0 \mathrm{~K}^{2} \mathrm{~s}^{-1}$ ), extending into the central and western $\mathrm{Eu}$ rope, while the areas of the Mediterranean and the Near East were covered with lower values (static stability values less than $1.2 \mathrm{~K}^{2} \mathrm{~s}^{-1}$ over central Mediterranean and less than $0.8 \mathrm{~K}^{2} \mathrm{~s}^{-1}$ over the area of the Near East), as the lower tro- pospheric air is relatively unstable in these latter areas (note that in late January the land is generally colder than the sea over the area).

From the distribution of the divergence of the horizontal wind vector at $850 \mathrm{hPa}$, as presented in Fig. 3, enhanced convergence (negative values denote convergence and positive values divergence) was noted just to the north of the Black Sea (less than $-20 \times 10^{-6} s^{-1}$ ), while much weaker lower tropospheric convergence was observed over the Mediterranean. From the distribution of the divergence of the horizontal wind vector over the upper troposphere (as calculated at the $300 \mathrm{hPa}$ isobaric level, but not presented), strong divergence (more than $20 \times 10^{-6} \mathrm{~s}^{-1}$ ) was found just to the north of the Black Sea, which, coupled with the lower tropospheric convergence over the same area, enhanced strong ascending motions and subsequent cloud formation.

At 00:00 UTC 27 January, in the middle and upper troposphere (500 and $300 \mathrm{hPa}$, respectively), a weak upper trough had just passed over Cyprus, leaving the area under the influence of a northwesterly upper flow. In the middle troposphere (Fig. 4), a minor trough was noted, extending from $48^{\circ} \mathrm{N}$ to $55^{\circ} \mathrm{N}$ and $20^{\circ} \mathrm{E}$ to $28^{\circ} \mathrm{E}$. This trough was ahead of a strong northwesterly jet stream, extending from the north of the British Isles towards the northwest of the Black Sea (see Fig. 4). Also, the distribution of the field of relative vorticity over the upper troposphere (see Fig. 4) exhibited positive values (denoting cyclonic behaviour at the upper troposphere) over the eastern Mediterranean, suggesting enhanced upward motions of air. On the contrary, the western Europe lied in an area of negative relative vorticity values, which denotes anticyclonic behaviour of the atmosphere (Fig. 4). The spot value over the island of Cyprus is $5 \times 10^{-5} \mathrm{~s}^{-1}$, while the area of maximum relative vorticity values (exceeding $8 \times 10^{-5} \mathrm{~s}^{-1}$ ) was found over Egypt, just ahead of the minor upper trough.

\subsubsection{January 2008}

Figure 5 displays the existence of significant lower tropospheric instability, covering the area of the Black Sea, Asia Minor, and the Aegean Sea at 00:00 UTC 28 January; at this time, the static stability index over the Black Sea was less than $0.7 \mathrm{~K}^{2} \mathrm{~s}^{-1}$ and over Cyprus was around $1 \mathrm{~K}^{2} \mathrm{~s}^{-1}$. Also, at this time, lower tropospheric convergence took place over Asia Minor and the Aegean which, in association with the divergence of the horizontal wind vector of the upper troposphere (calculated but not presented), denotes ascending motion and cloud formation.

Compared to 00:00 UTC 27 January, significant changes were noted after $24 \mathrm{~h}$, when the trough at $500 \mathrm{hPa}$ (see Fig. 6) has extended and notably deepened. Progressing southeastwards and with its axis extending from the northwest of the Black Sea to South Greece, the observed pattern enhanced further the depression's deepening. The polar jet progressed eastwards, strengthened and veered to meridional. Negative 


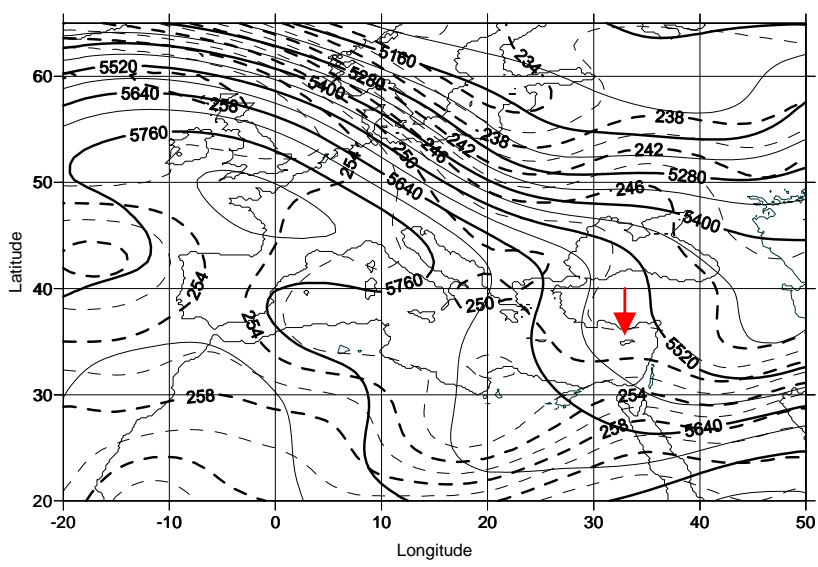

(a)

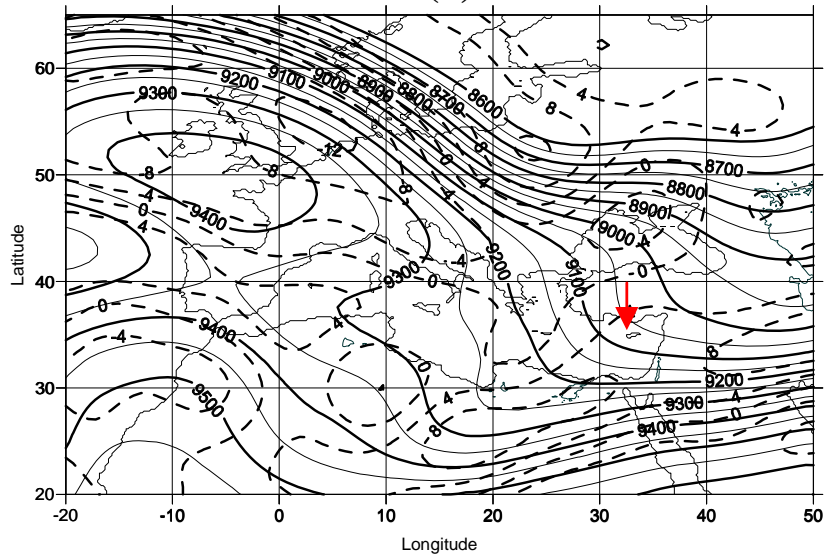

(b)

Fig. 4. (a) Geopotential height (solid lines, unit: gpm) and temperature (dashed lines, unit: $\mathrm{K}$ ) at the isobaric level of $500 \mathrm{hPa}$ (a); (b) geopotential height (solid lines, unit: gpm) and relative vorticity (dashed lines, unit: $\times 10^{-5} \mathrm{~s}^{-1}$ ) at the isobaric level of $300 \mathrm{hPa}$, at 00:00 UTC 27 January 2008. The red arrow point to Cyprus area.

relative vorticity values at the upper troposphere covered central and west Europe, as a result of the anticyclonic jet stream's curvature; the areas of the eastern Mediterranean and Egypt were characterized by positive relative vorticity values, ahead of the upper trough (see Fig. 6). As a result of the middle and upper tropospheric driving mechanisms, significant changes took place within the lower troposphere.

\subsubsection{January 2008}

At 00:00 UTC 29 January, low values of static stability index were located over the areas of the Aegean and the eastern Mediterranean, representing a remarkable instability at the lower tropospheric layers (see Fig. 7). From the distribution of divergence, an area of lower tropospheric convergence covering the eastern Mediterranean, north Syria and east Asia Minor was formed which, in association with the

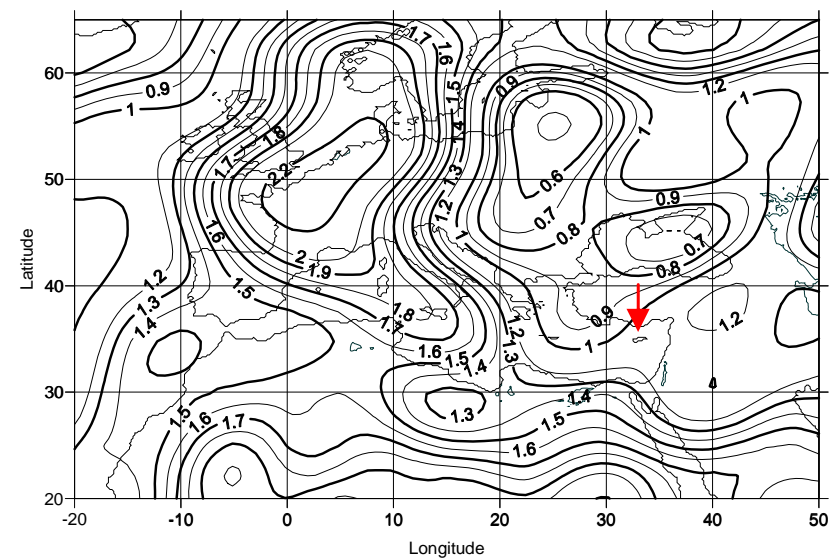

(a)

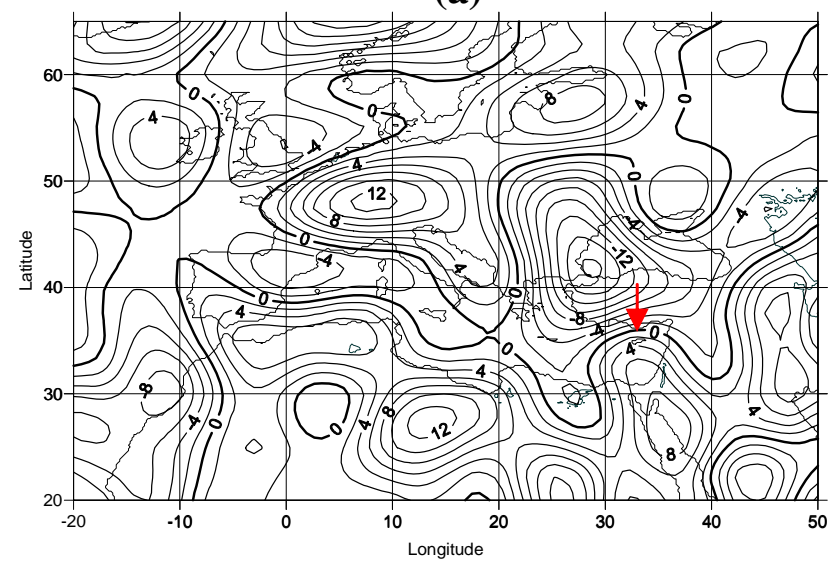

(b)

Fig. 5. As Fig. 3, but for 00:00 UTC 28 January 2008.

upper tropospheric divergence ( $300 \mathrm{hPa}$ divergence) over the same area (calculated but not presented) denotes enhanced ascending motion and cloud formation. The infra-red satellite image of Fig. 8 displays the extensive cloud formations covering the eastern Mediterranean area corresponding to this time.

At this time, the trough extended further southwards, reaching the area of Cyprus, with its axis just to the west of the island (see Fig. 9). From the shape of the trough, it can be suggested that the trough tends to become cut-off from the general circulation; nevertheless, its sharp curvature still provides adequate cyclonic vorticity for intense weather phenomena to continue to occur. At $300 \mathrm{hPa}$, the jet had split into two parts: one ahead and the other behind the upper trough's axis (see Fig. 9) The geopotential height at $500 \mathrm{hPa}$ over Cyprus has decreased by $150 \mathrm{gpm}$ in a $48 \mathrm{~h}$ period, lowered to $5400 \mathrm{gpm}$. At the $300 \mathrm{hPa}$ isobaric level, enhanced cyclonic circulation over the area of interest was observed, due to the positive values of the relative vorticity field over the study region; the spot value over Cyprus was at this time $8 \times 10^{-5} \mathrm{~s}^{-1}$, supporting further cyclonic development. It 


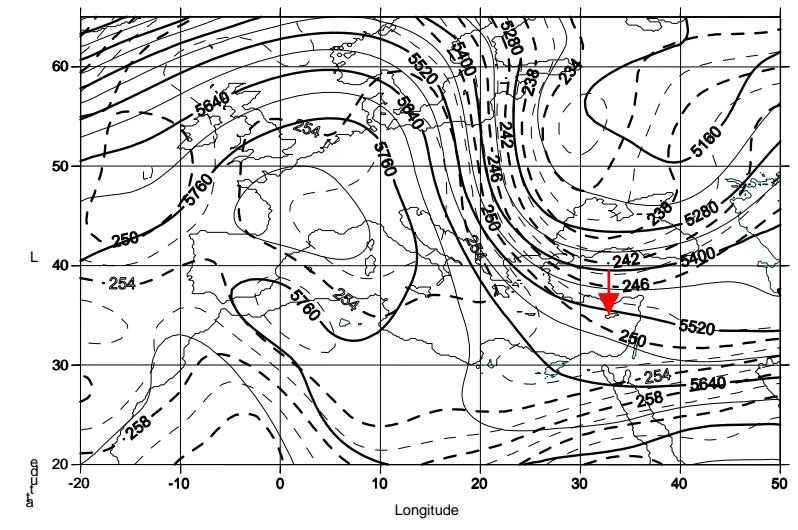

(a)

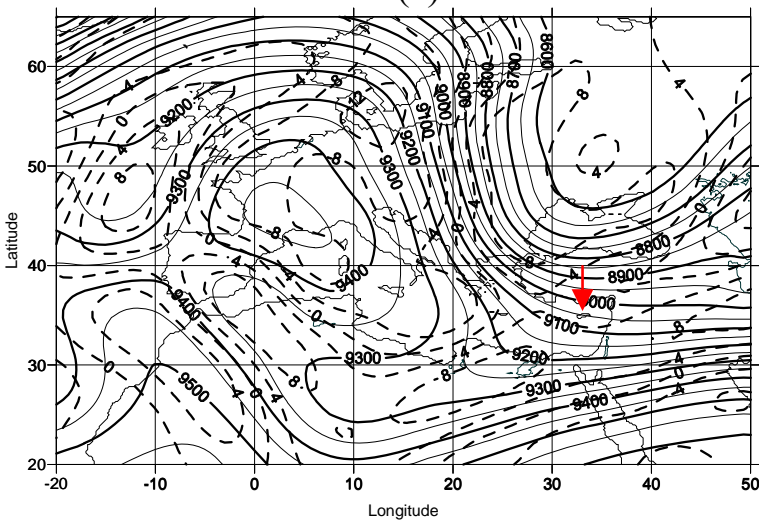

(b)

Fig. 6. As Fig. 4, but for 00:00 UTC 28 January 2008.

is worth mentioning that the shear of the advancing upper trough was the driving mechanism for the development at the upper levels.

\subsubsection{January 2008}

At 00:00 UTC 30 January, the last day in the present analysis, the area of the central and eastern Mediterranean was characterised by lower tropospheric instability (Fig. 10), while stable air was found over the Balkans. From the distribution of the divergence of the horizontal wind vector over the lower troposphere (Fig. 10) the area of convergence was located at the time eastwards, namely, over east of Asia Minor. The associated cloud bands have subsequently progressed eastwards.

At this time, although the trough has relaxed (Fig. 11), its axis remained over Cyprus and a slight further decrease in the geopotential heights was noted in the middle troposphere (5380 gpm). At the upper troposphere, the trough was giving signs of relaxation, while moving eastwards. The relative vorticity over the area of Cyprus was preserved, while the geopotential height exhibited a further fall (spot value over Cyprus: 8950 gpm; see Fig. 11).

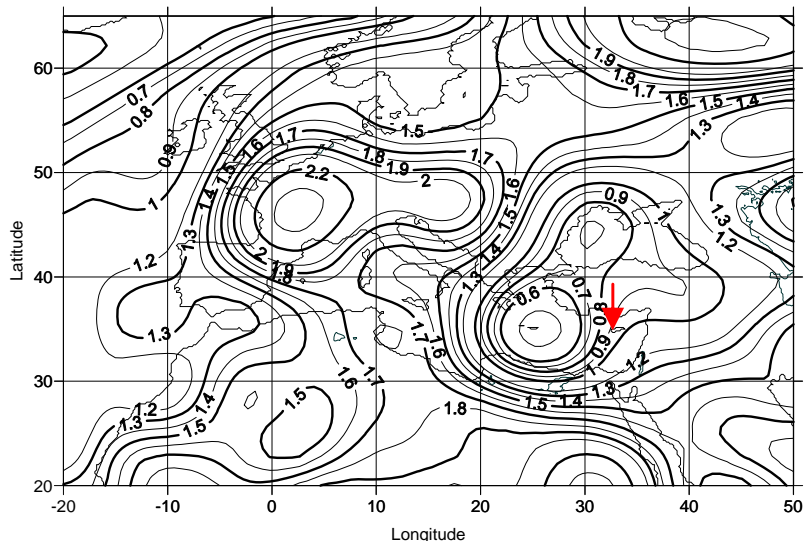

(a)

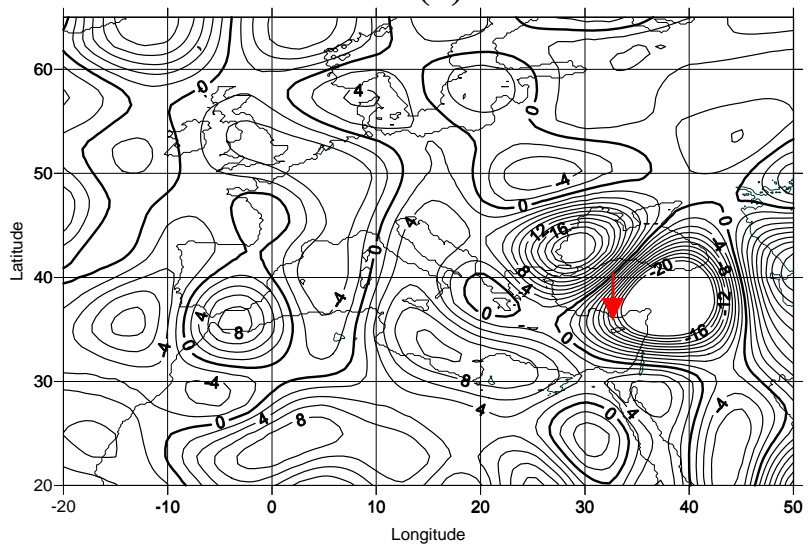

(b)

Fig. 7. As Fig. 3, but for 00:00 UTC 29 January 2008.

\subsection{Thermodynamic study}

The thermodynamic behaviour of the troposphere over the area of Cyprus during the study period was examined by studying selected stability indices, using the radiosonde data collected at Athalassa station at 06:00 UTC and 12:00 UTC. For the needs of the thermodynamic study, the RAOB software was used. RAOB is a very powerful and innovative sounding analysis software. It automatically decodes data from 35 different formats and plots data on 10 interactive displays including skew-Ts, Tephigrams, hodographs and crosssections. It produces displays of over 100 atmospheric parameters including icing, turbulence, wind shear, clouds, inversions, stability indices and much more (for further reference to RAOB, see http://www.raob.com/displays.php). The definition, formulation and interpretation of the various thermodynamic parameters are available online (http://www.crh. noaa.gov/lmk/soo/docu/indices.php). More details on the practical usage of thermodynamic indices are given by Carlson (1991) and Ramis and Tudurí (1997). All the abbreviations used in this paper are summarized in the Appendix. 


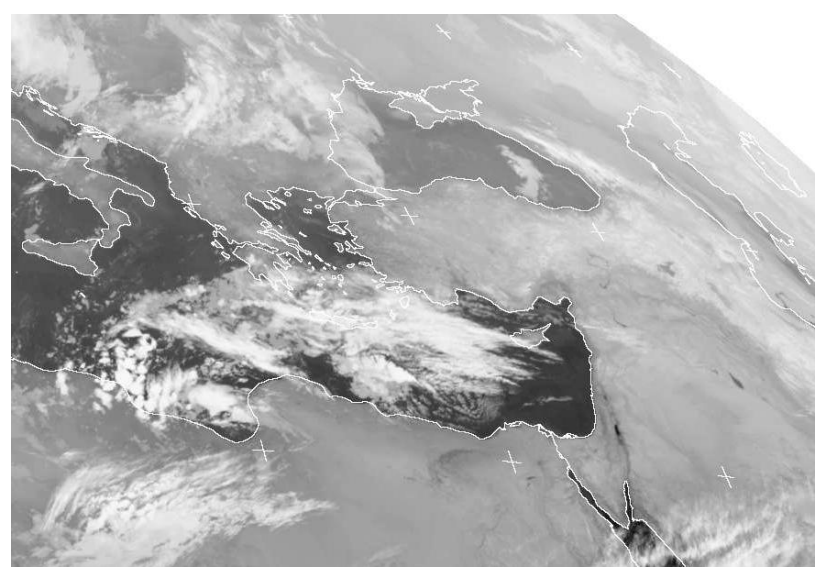

Fig. 8. Meteosat infra-red image (MSG-2, $10.8 \mu \mathrm{m}$ ) for 00:00 UTC 29 January 2008. Copyright 2010 EUMETSAT.

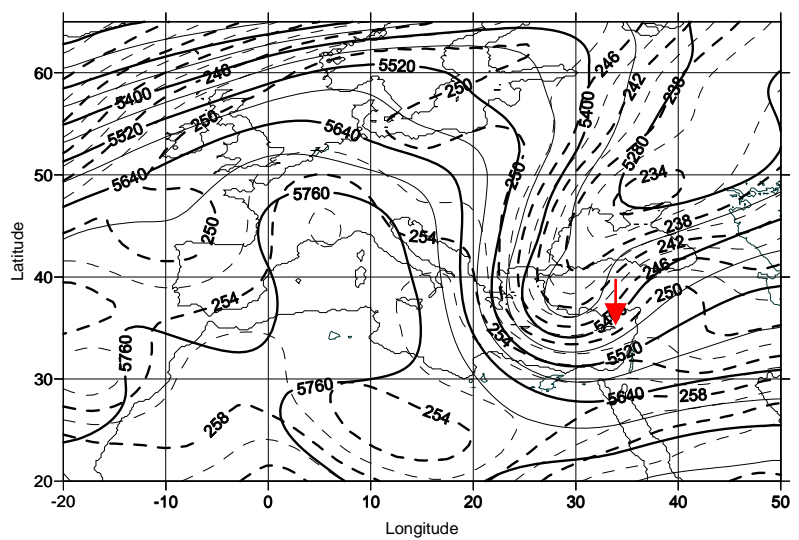

(a)

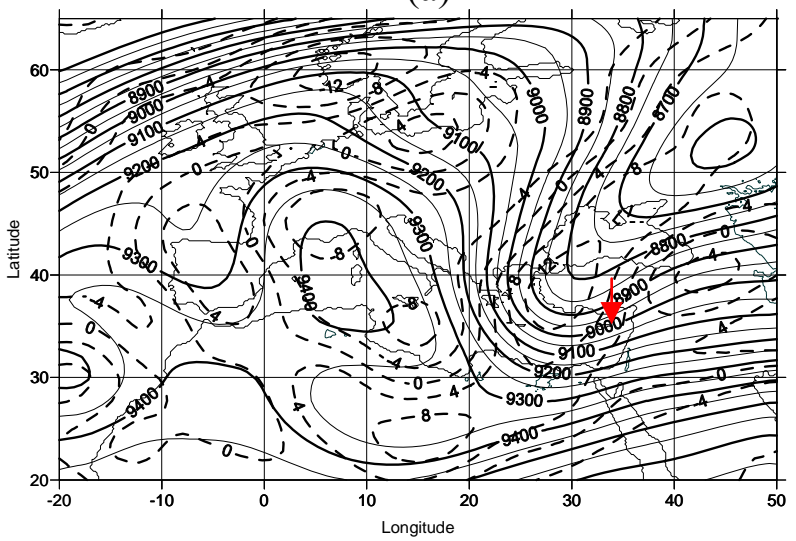

(b)

Fig. 9. As Fig. 4, but for 00:00 UTC 29 January 2008.

From the calculation of several thermodynamic indices/parameters which are considered in the literature to be associated with convective and/or severe weather, it did not

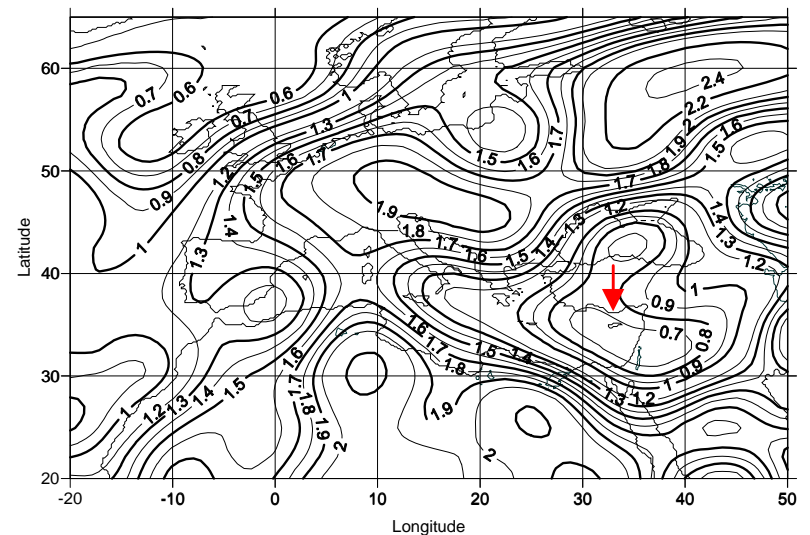

(a)

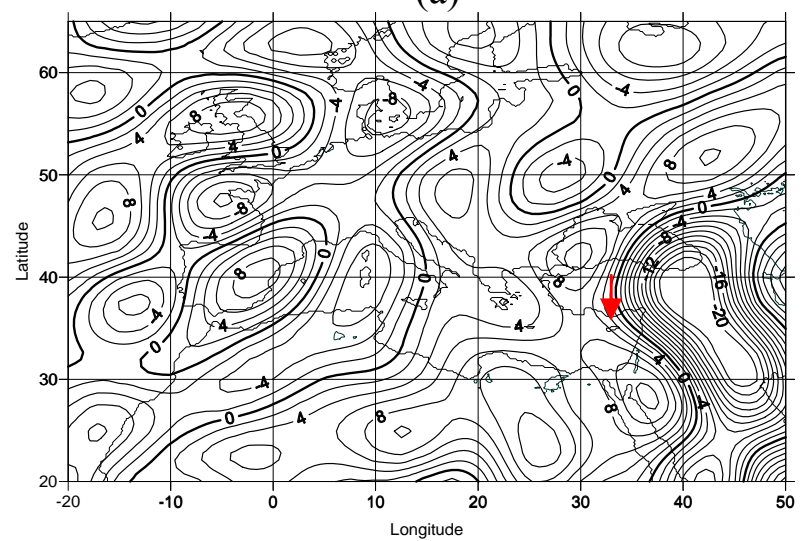

(b)

Fig. 10. As Fig. 3, but for 00:00 UTC 30 January 2008.

become evident that they could envisage such phenomena over Cyprus. These indices/parameters are the Convective Inhibition (CIN), Vorticity Generator Parameter (VGP), Bulk Richardson Number (BRN), the vertical extent of the convective cloud above freezing level (EL-FZ), the cloud top temperature (CTT), Energy Helicity Index (EHI) and Downdraft Convective Available Potential Energy (DCAPE). Also, it is worth noting that neither Convective Available Potential Energy (CAPE) nor Lifted Index (LI), which are widely used as thermodynamic indices for thundery activity, resulted in values suggestive of severe weather (Michalopoulou and Jacovides, 1987; Jacovides and Yonetani, 1990). This may be partially attributed to the fact that thermodynamic factors, alone, were not sufficient to lead to thunderstorms and/or hail. In addition, the values of other indices and parameters compared to those found in the literature (see Table 1), suggest that the potential of the troposphere for severe weather was weak, apart from three indices: KO index, BRNshear and the Level of Free Convection (LFC), which suggested high potential and the Total Totals index (TT), which suggested moderate potential of thunderstorms and/or hail to occur. By comparing the observed values with the suggested 
Table 1. Thermodynamic indices calculated for Athalassa radiosonde station during the study period, for 06:00 and 12:00 UTC. Based on literature, numbers in red indicate strong probability and numbers in green moderate probability for thundery activity.

\begin{tabular}{lllllllll}
\hline $\begin{array}{l}\text { Date } \\
\text { Time } \\
\text { (UTC) }\end{array}$ & \multicolumn{2}{c}{ 27 Jan 2008 } & \multicolumn{2}{c}{ 28 Jan 2008 } & \multicolumn{2}{c}{ 29 Jan 2008 } & \multicolumn{2}{c}{ 30 Jan 2008 } \\
\hline SWEAT & 33 & $12: 00$ & $06: 00$ & $12: 00$ & $06: 00$ & $12: 00$ & $06: 00$ & $12: 00$ \\
KO & 9.3 & 1.7 & 7.2 & -0.7 & 0 & 0 & 5.8 & 4.9 \\
K & 9.1 & - & 8.5 & 20.1 & 27 & 18.4 & 61 & 6.5 \\
TT & 43.4 & 44.2 & 50 & 50 & 55 & 54.3 & 41.6 & 42 \\
LI & 10.4 & 5.1 & 9.7 & 1.3 & 2.3 & 2.2 & 9.5 & 6.8 \\
WBZ & 2127 & 3748 & 3900 & 5202 & 3545 & 2679 & 808 & 344 \\
SRH & 19 & 52 & 207 & 133 & 94 & 110 & - & 21 \\
BRNsh & 1.6 & 11.7 & 10.7 & 63.9 & 14.1 & 74.1 & 4.6 & 58.6 \\
LFC & - & - & - & 813 & 1744 & 920 & 1839 & 798 \\
\hline
\end{tabular}

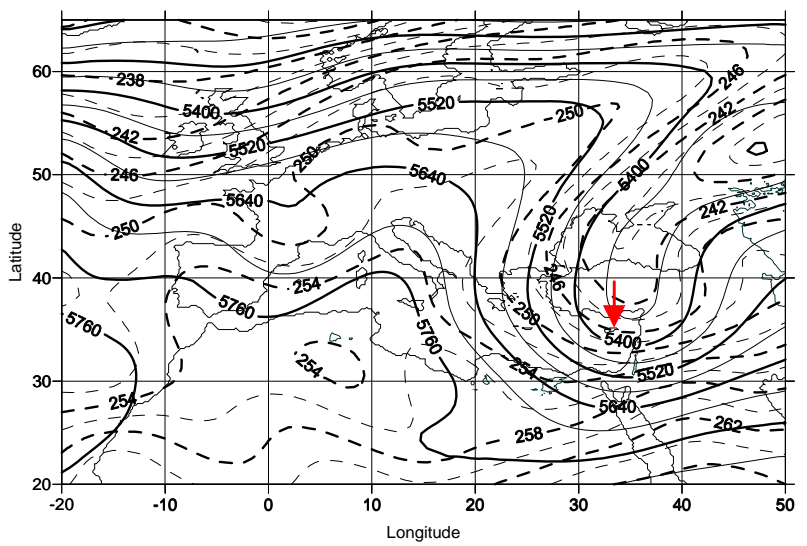

(a)

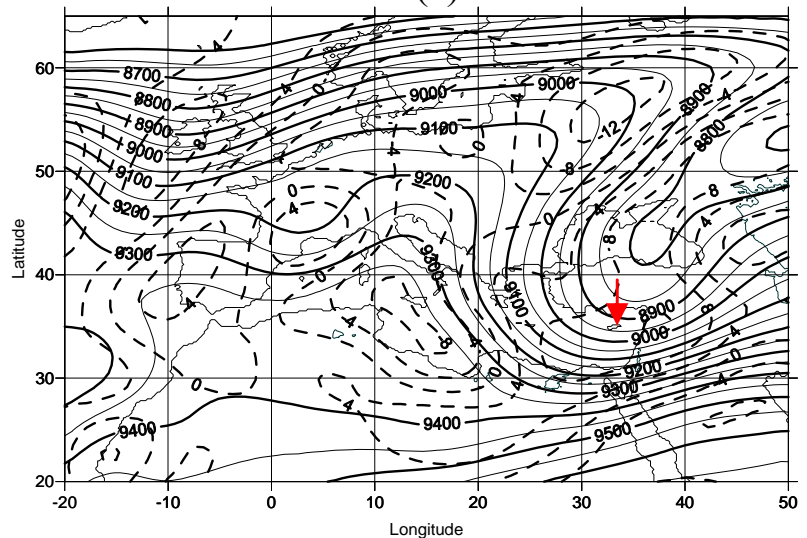

(b)

Fig. 11. As Fig. 4, but for 00:00 UTC 30 January 2008.

thresholds by Savvidou et al. (2009) for the area of Cyprus, it can be deduced that the TT index suggested potentially extreme thunderstorm events on 29 of January, while the value on the 28 January exceeded the winter observed threshold $\left(49.8^{\circ} \mathrm{C}\right)$. The LI index resulted in less indicative results, without suggesting thunderstorm potential, compared to the TT index. This can be attributed to the fact that the LI Index does not take into account the moisture content at the lower levels. This additional information which is taken into account for the calculation of the TT Index increases its values and consequently can be considered as more effectively marking the thunderstorm potential. The Storm Relative Helicity (SRH) reached notably high values on 28 and 29 January, exceeding the suggested thresholds for potentially extreme thunderstorm events $(74 \mathrm{JKg}-1)$. Similarly, as presented in Table 1, the BRNsh values observed on the 28, 29 and 30 January signify the potential for extreme thunderstorm events to occur (threshold suggested by Savvidou et al. (2009): $43.3 \mathrm{Jkg}-1$ ).

Selected tephigrams for Athalassa radiosonde station are presented in Fig. 12. At 06:00 UTC 28 January, the respective tephigram supports the presence of scattered to broken layer cloud between $4000 \mathrm{~m}$ and $7000 \mathrm{~m}$. At 12:00 UTC 28 January, increased amounts of both cumuliform and stratiform cloud with lower bases are supported by the troposphere's vertical profile, with a significant layer of medium cloud between $3500 \mathrm{~m}$ and $7000 \mathrm{~m}$. Thick cloud layers with the lowest bases at $100 \mathrm{~m}$ and extending up to $5500 \mathrm{~m}$ are sustained at 06:00 UTC 29 January. Broken to overcast sky condition is demonstrated on the 06:00 UTC 29 January tephigram, with cloud formations between $100 \mathrm{~m}$ and $5500 \mathrm{~m}$. Finally, at 12:00 UTC 29 January, overcast conditions continued to affect the area, but with much lower vertical extent: from $1000 \mathrm{~m}$ top $2500 \mathrm{~m}$; at the same time, the amount of medium cloud was decreased.

\subsection{Energetic study}

For the study of the system's energetics, a quasi-Lagrangian approach was adopted. In such an approach, the energetic calculations are carried out in an area surrounding the synoptic-scale system, as this is identified at the $500 \mathrm{hPa}$ 


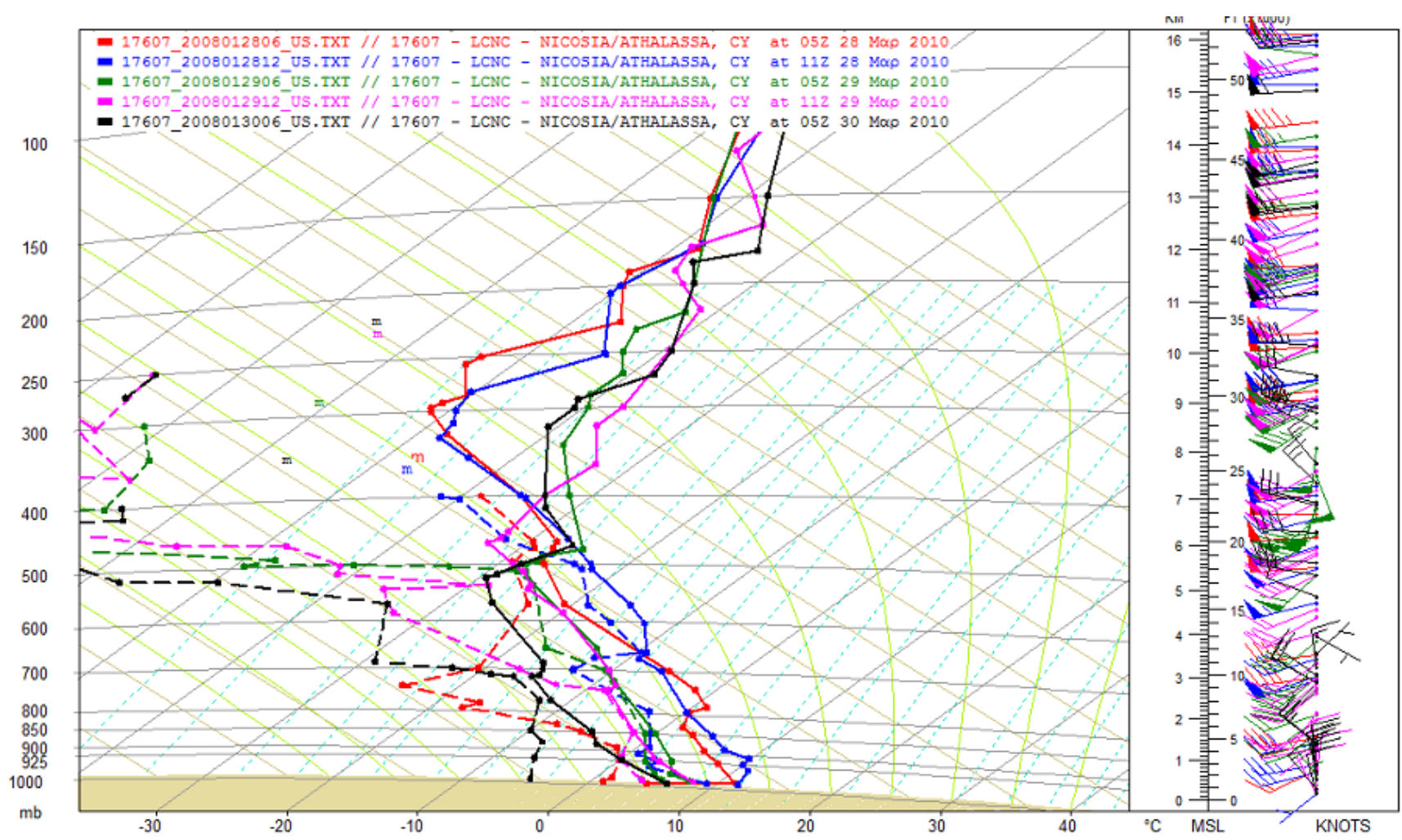

Fig. 12. Selected tephigrams for Athalassa radiosonde station. The release time 05:00 UTC or 11:00 UTC is indicated corresponding to the 0600UTC and 1200UTC synoptic times, respectively. The scale on the right is in km (left part) and 1000s of feet (right part).

level; hence, this area is not fixed in time but moves along with the system's spatial evolution. A similar approach was adopted by Michaelides et al. (1999). Table 2 displays the longitudinal and latitudinal lateral boundaries of the area which surrounds the system. In the vertical, ten standard levels were used, namely 1000, 850, 700, 500, 400, 300, 250, 200, 150 and $100 \mathrm{hPa}$. This quasi-Lagrangian approach is adopted so that the energetics calculations focus more on the individual synoptic system and therefore these reflect its characteristics, to a large extent.

The main forms of atmospheric energy within a system are the zonal available potential energy (ZAPE), eddy available potential energy (EAPE), zonal kinetic energy (ZKE) and eddy kinetic energy (EKE) (Michaelides, 1987, 1992). These forms of energy were calculated for the open area surrounding the depression, as explained above. The conversions from one form of energy to another were also calculated; the most significant ones are the conversions from ZAPE to EAPE, from EAPE to EKE, from EKE to ZKE and from ZAPE to ZKE.

Due to the fact that an open weather system is not isolated and adiabatic from its surroundings, energy can enter or exit the system through its boundaries, in such a way that the system is either supplied with energy or energy is extracted from
Table 2. Horizontal boundaries of the area that was used for the energetic calculations.

\begin{tabular}{lll}
\hline Date - Time (UTC) & $\begin{array}{l}\text { Longitude } \\
\left({ }^{\circ} \mathrm{E}\right)\end{array}$ & $\begin{array}{l}\text { Latitude } \\
\left({ }^{\circ} \mathrm{EN}\right)\end{array}$ \\
\hline 27 Jan 2008 - 00:00 & $10-40$ & $40-70$ \\
28 Jan 2008 - 00:00 & $20-50$ & $35-65$ \\
29 Jan 2008-00:00 & $20-50$ & $20-50$ \\
30 Jan 2008-00:00 & $25-55$ & $15-45$ \\
31 Jan 2008-00:00 & $30-60$ & $15-45$ \\
\hline
\end{tabular}

it. The transfer of the four forms of energy to or from the system's boundaries was also studied.

The calculations of all the aforementioned energetic components were performed for 00:00 UTC on 27 to 31 January 2008. 29 January is considered to be "Day 0" denoted by D0; similarly, D-2, D-1, D+1 and D+2 refer to the $27,28,30$ and 31 January 2008, respectively.

The major forms of energy for all days were the zonal energies: ZKE and ZAPE (Fig. 13). ZAPE obtained its maximum values within the medium tropospheric layers, where the zonal baroclinic component was more pronounced. The substantial weakening of baroclinicity in the stratospheric 


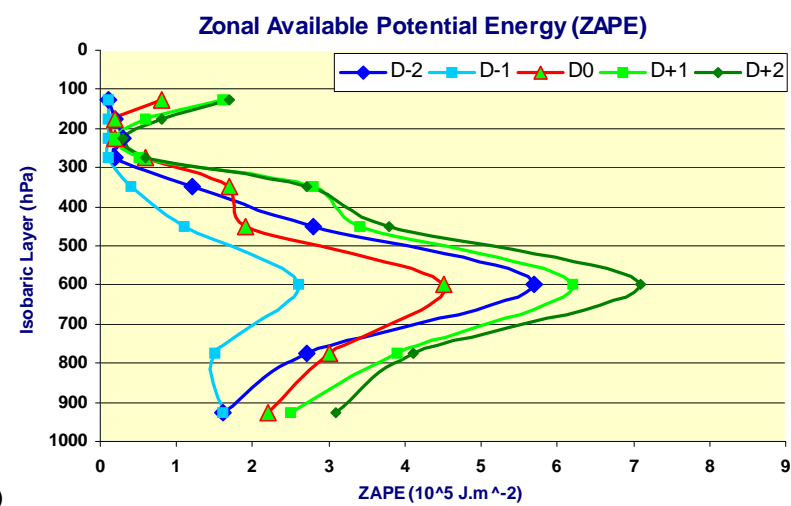

(a)

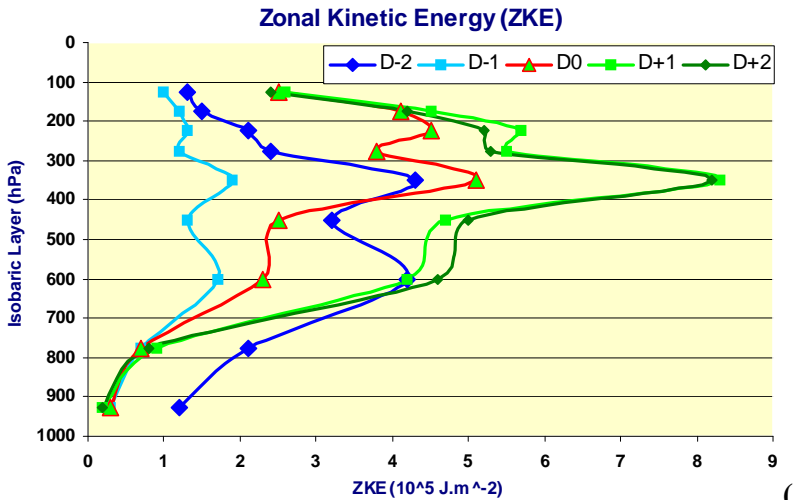

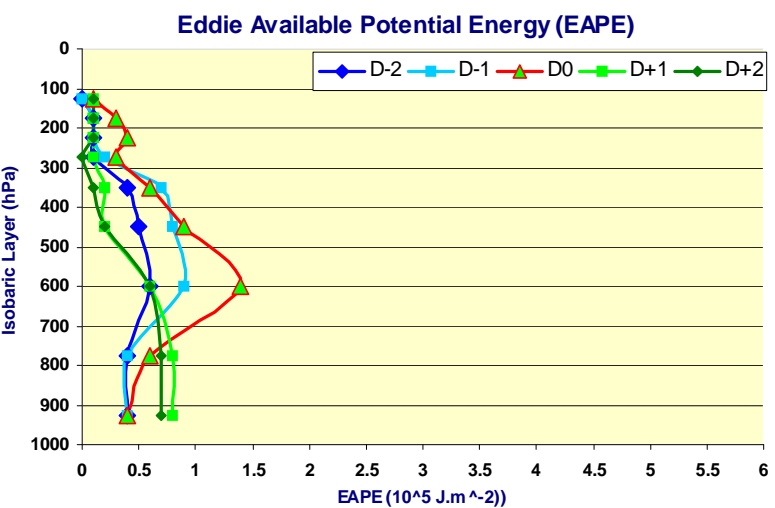

Eddie Kinetic Energy (EKE)

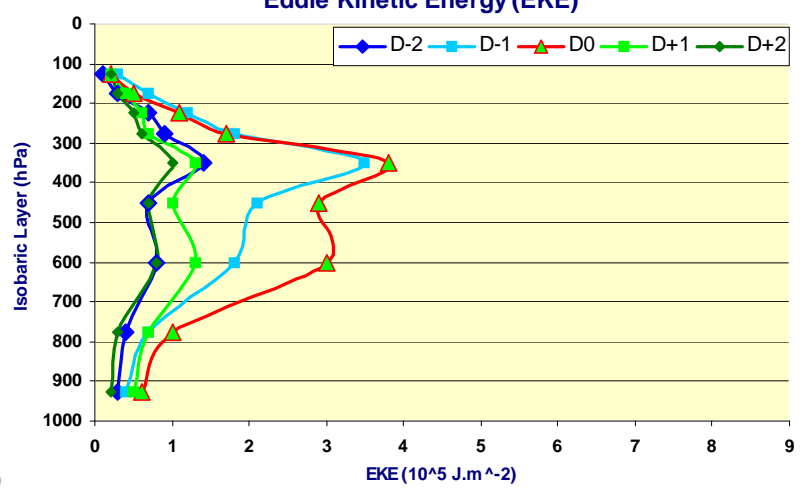

Fig. 13. Vertical distribution of (a) ZAPE, (b) EAPE, (c) ZKE, and (d) EKE on 27 (D-2), 28 (D-1), 29 (D0), 30 (D+1) and 31 January 2008 $(\mathrm{D}+2)$.

layers was reflected in the very low values within these layers. On the contrary, ZKE obtained its maximum values at the jet stream level. The larger values of ZAPE were calculated after the passage of the depression, D+1 and D+2, while relatively high ZAPE was also found on D-2, but still lower than the ZAPE after the depression's passage. Similar results were found for ZKE; only on 28 January, the values were relatively lower. This can possibly be attributed to the fact that ZKE has been converted to EKE (see discussion below).

The approach of the depression was related to a gradual increase of the values of the eddy energies, while when it moved away, the opposite happened: EAPE and EKE noted a gradual increase from 27 until 29 and a decrease thereafter.

The conversions from one type of energy to another within the system are presented in Fig. 14. Note that the scale of $x$-axis is different on each graph for better representation. It appears that the most significant conversion (in terms of absolute values) was the one from ZAPE to EAPE, within most of the tropospheric layers. The maxima were noted in the middle and upper troposphere, except on D+1. It is worth mentioning that at D-1 and D+1 and at the lowest levels at D-2, EAPE was converted to ZAPE (negative values on the graph).
The conversion of EAPE to EKE was close to zero, although small amounts of EAPE were converted to EKE. Nevertheless, on the two days of the main interest, namely, 28 and 29 January, some amounts of EKE were converted to EAPE in the layer between $500 \mathrm{hPa}$ and $300 \mathrm{hPa}$.

Concerning the conversion of ZKE to EKE, a net conversion is noted throughout the troposphere, especially on the two days of main interest; this is more pronounced at the level of $350 \mathrm{hPa}$. Smaller amounts of energy conversions were found after the depression's passage, while at D-2, EKE was converted to $\mathrm{ZKE}$. The latter conversion could be related to the first weak trough preceding the studied depression, which was still affecting Cyprus.

The conversion of ZKE to ZAPE was well-defined, mainly over the middle and upper tropospheric layers during D0, $\mathrm{D}+1$ and D+2, while on D-1 and D-2 an inverse conversion was found.

By looking at the energy transfers to and from the system's surroundings (see Fig. 15), it can be seen that a notable extraction of ZKE (BKZ) from the system at the upper levels took place on D0 and the subsequent days. On the contrary, on the days preceding the depression's passage the system had gained significant amounts of zonal kinetic energy from its environment. Eddy kinetic energy (EKE) has been noted 
(a)
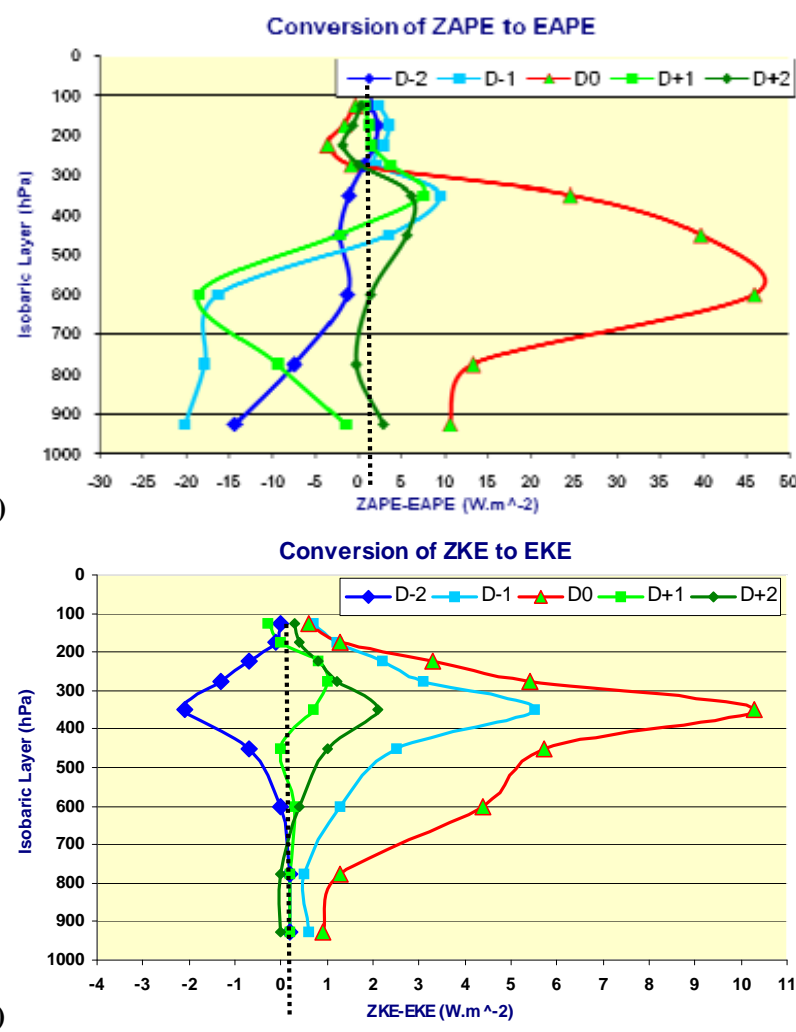

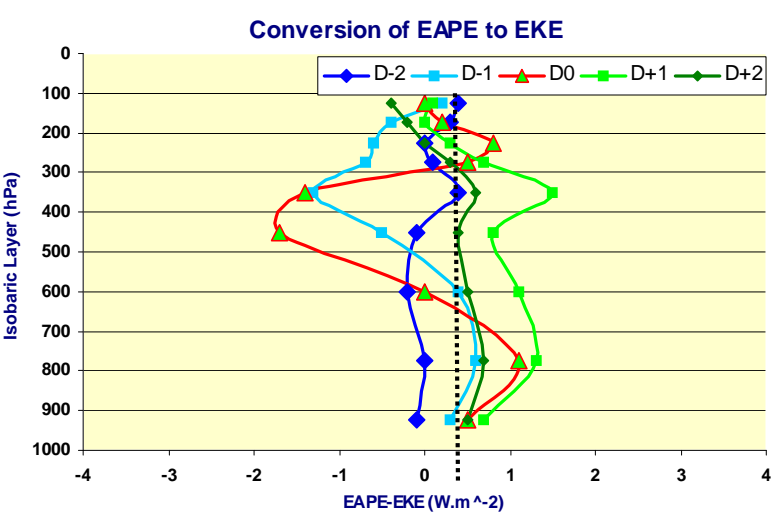

(b)

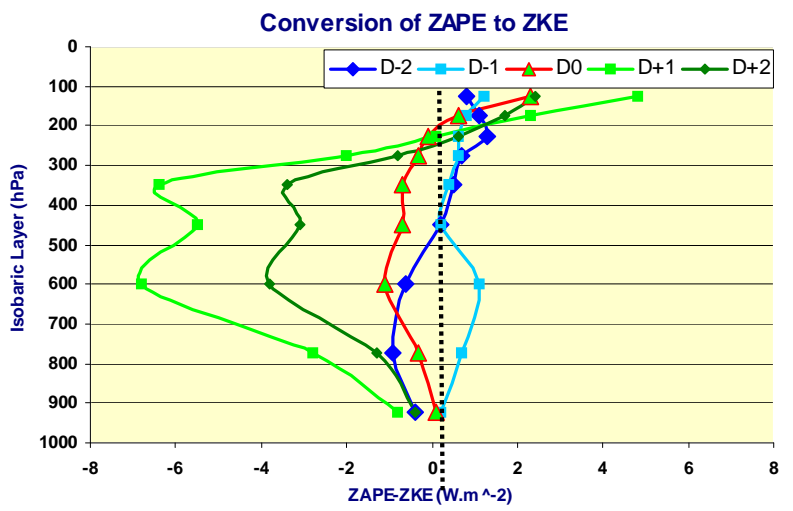

Fig. 14. Energy conversions of (a) ZAPE to EAPE, (b) EAPE to EKE, (c) ZKE to EKE, and (d) ZAPE to ZKE (d) on 27 (D-2), 28 (D-1), 29 (D0), 30 (D+1) and 31 January 2008 (D+2).

to enter into the system on all of the five days studied but 29 January when a significant loss of EKE from the system was noted (BKE).

More complicated results were found concerning the available potential energy transfers, namely BAZ and BAE. The system exhibited an overall transfer of ZAPE to its surroundings at the middle levels of the troposphere, but received ZAPE at the lower and upper levels, at all times. The system gained EAPE on the days preceding the trough's passage; it also gained some amounts at D0, from the lower and middle tropospheric layers. On the contrary, EAPE has been transferred into the system's environment after the passage and at D0 in the upper troposphere.

\section{Concluding remarks}

The present work focused on the cold frontal depression that affected the area of Cyprus from 27 to 29 January 2008. In this respect, synoptic, dynamic, energetic and thermodynamic analyses were performed. The depression originated from the north-northwest of the area of Cyprus, but rapidly developed into a frontal depression over the island, with an intense baroclinic character. The associated phenomena were those of a typical cold frontal depression. The jet stream's curvature and positioning and the associated upper dynamics were the main contributing factors to the observed intense weather phenomena. The contribution of the Mediterranean Sea was also quite significant, since the lower tropospheric convergence was enhanced by increased vertical heat fluxes through the interaction of the relatively warmer sea and the colder airmass advancing from north.

Convergence in the lower and divergence in the upper troposphere, resulted in intense ascending motion over the area, enhanced cloud formation and thundery activity on 28,29 and initially on 30 January. In addition to the dynamic and thermodynamic influences, Maheras et al. (2001) emphasized the diurnal influence of two factors on a cyclone's intensity: the effect of the sea and the role of the Anatolian mountains. Recently, Ziv et al. (2010) have analyzed the role of a conveyor belt in frontal cyclonic systems in the Mediterranean region (within the framework of the traditional mid-latitude conveyor belt model). In this respect, they noted that there exists a notable diversity in the characteristics of Mediterranean cyclones; hence, generalizations are not easy to make. However, they noted the important role of the conveyor belt in cloud formation; in addition, they stressed the importance of the vertical moisture fluxes (i.e., convection) from the warmer Mediterranean waters, in line 


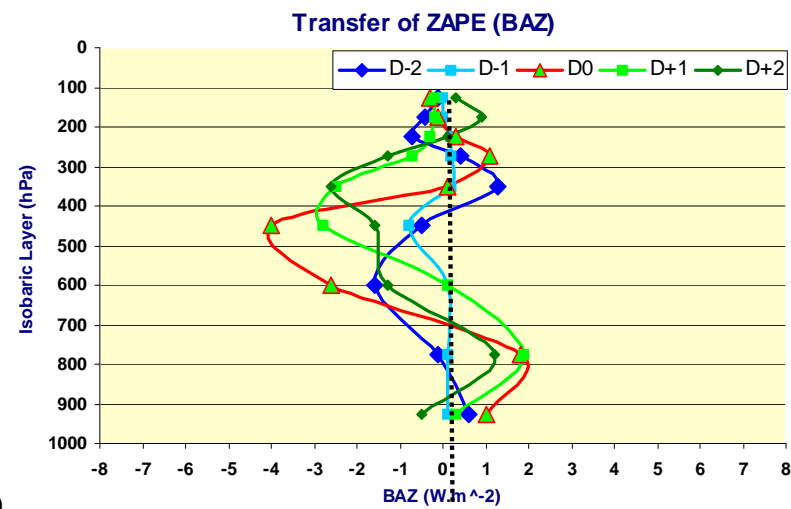

(a)

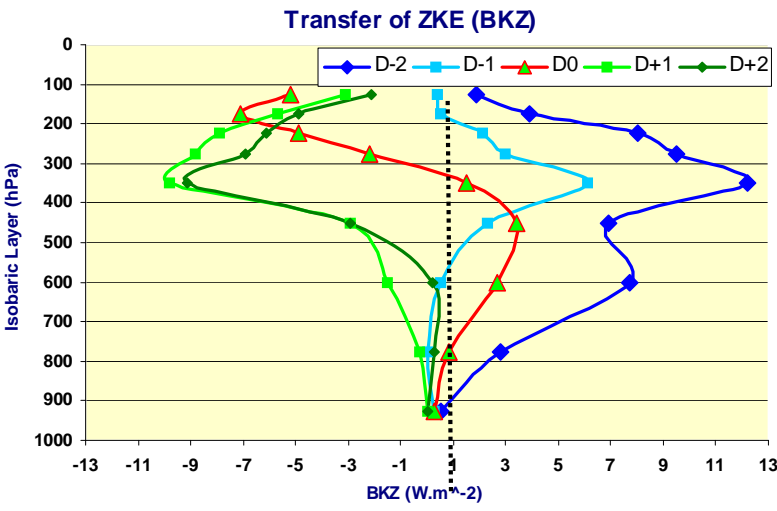

(c)

(d) (b)
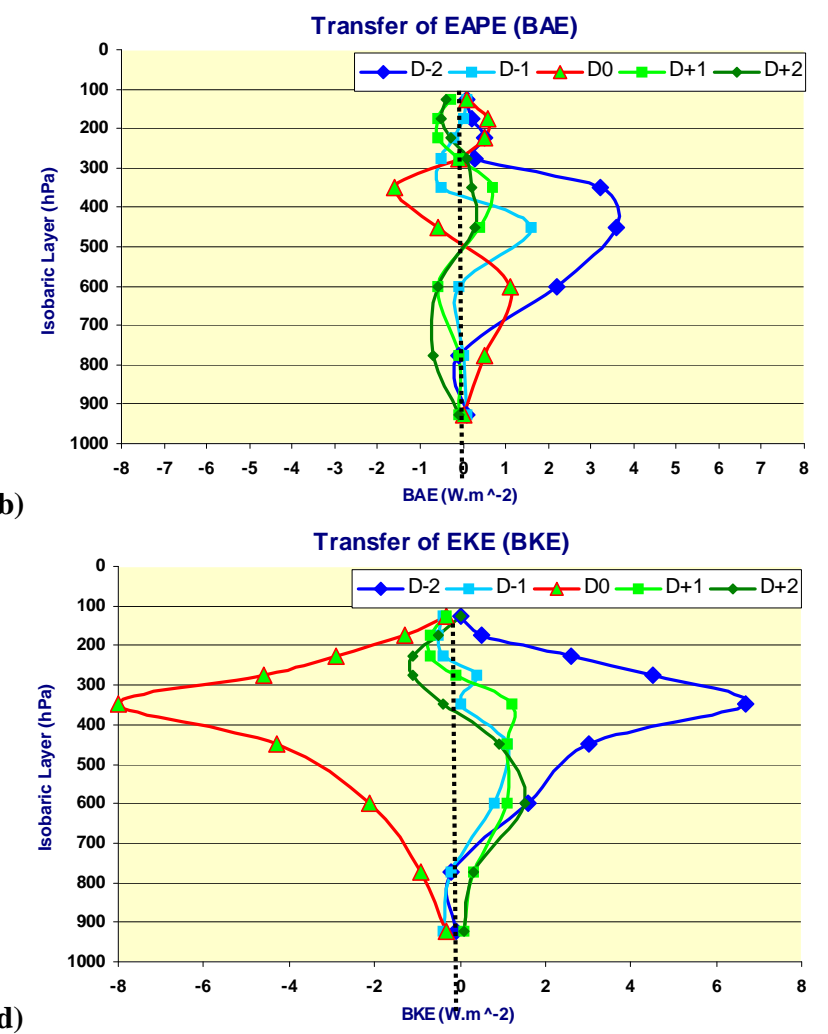

Fig. 15. Energy transfers of (a) ZAPE, (b) EAPE, (c) ZKE and (d) EKE on 27 (D-2), 28 (D-1), 29 (D0), 30 (D+1) and 31 January 2008 $(\mathrm{D}+2)$.

with findings by other researchers (e.g., Shay-El and Alpert, 1991; Stein and Alpert, 1993).

Trigo et al. (1999) stated that the major steering mechanisms of depressions in the Mediterranean, associated either with large-scale circulation regimes (e.g., low-level baroclinicity) or local effects (e.g., induced by sea-land contrast or local orography) are much unexplored.

By comparing the tropospheric characteristics in the present study to those analyzed in another study by Nicolaides et al. (2008), many similarities are noted; for example, the spatial and temporal evolution of the low level instability index and that of the divergence field were found to follow similar patterns.

The energetic analysis showed that energy was transferred at the higher tropospheric levels (i.e., jet stream levels) into the system. The energy was found to be gained during the days prior to D0 (i.e., D-2 and D-1) and to be lost to the environment during the following days (i.e., D0, D+1 and $\mathrm{D}+2)$.

From the thermodynamic study, the KO index, the BRNsh and the LFC suggested a probability of hailstorms. Taking into account the modified thresholds for the area of Cyprus (Savvidou et al., 2009), the SRH and the TT indices also pointed out the potential for extreme thunderstorm events.
The results of the thermodynamic analysis from the present study were compared to the results from a baroclinic depression analyzed by Nicolaides et al. (2008). Thermodynamic indices, such as TT and BRNsh were found to have higher values (compared to Nicolaides et al., 2008), pointing out the existence of instability, while some of them suggested prevailing thunderstorms, tornadic activity and hailstorms over the area of Cyprus.

The utilization of thermodynamic indices is very important and can shed light on various aspects of the cyclone's development. In the present study, a number of thermodynamic indices have been explored but other indices can also be considered. For example, Lynn and Yair (2010) have recently developed a new Lightning Potential Index (LPI) for evaluating the potential for lightning activity from weather forecast model output data. Such an index can form part of an investigation in future work encompassing lightning activity over the area.

Ziv et al. (2009) illustrate the complexity of the required conditions for thunderstorm development in the Eastern Mediterranean. More specifically, they investigated the significance of several factors on thunderstorm development in the eastern Mediterranean; they concluded that thunderstorm development is the result of a number of thermodynamic and 
dynamic factors. The present study confirms the postulation that a combination of thermodynamic and dynamic factors drives the evolution of severe weather phenomena in the area and that for the comprehensiveness of a diagnostic study of such phenomena, the thermodynamic and dynamic structures must be taken into consideration.

\section{Appendix A}

\section{Explanation of abbreviations}

\begin{tabular}{|c|c|}
\hline BAE, & $\begin{array}{l}\text { Boundary transfer of eddy available } \\
\text { potential energy }\end{array}$ \\
\hline BAZ, & $\begin{array}{l}\text { Boundary transfer of zonal available } \\
\text { potential energy }\end{array}$ \\
\hline BKE, & Boundary transfer of eddy kinetic energy \\
\hline BRN, & Bulk Richardson Number \\
\hline BRNsh, & BRN Shear \\
\hline BKZ, & Boundary transfer of zonal kinetic energy \\
\hline CAPE, & Convective available potential energy \\
\hline CIN, & Convective Inhibition \\
\hline CTT, & Cloud top temperature \\
\hline $\mathrm{D}+1$ & Day +1 \\
\hline $\mathrm{D}+2$, & Day +2 \\
\hline D0, & Day 0 \\
\hline D-1, & Day -1 \\
\hline D-2, & Day -2 \\
\hline DCAPE, & $\begin{array}{l}\text { Downdraft convective available } \\
\text { potential energy }\end{array}$ \\
\hline EAPE, & Eddy available potential energy \\
\hline EKE, & Eddy kinetic energy \\
\hline EL-FZ, & $\begin{array}{l}\text { Vertical extent of the convective cloud } \\
\text { above freezing level }\end{array}$ \\
\hline EHI, & Energy Helicity Index \\
\hline $\mathrm{K}$, & $\mathrm{K}$ index \\
\hline $\mathrm{KO}, \mathrm{KO}$ index, & $\begin{array}{l}\mathrm{KO}=0.5 \\
\left(\Theta_{e 500}-\Theta_{e 700}\right)-0.5\left(\Theta_{e 850}-\Theta_{e 1000}\right) \\
\text { where } \Theta_{e x} \text { is the equivalent potential } \\
\text { temperature at } \mathrm{X} \text { isobaric level }\end{array}$ \\
\hline LFC, & Level of free convection \\
\hline LI, & Lifted Index \\
\hline LPI, & Lightning Potential Index \\
\hline MSLP, & Mean sea level pressure \\
\hline NCAR, & National Center for Atmospheric Research \\
\hline NCEP, & $\begin{array}{l}\text { National Centers for Environmental } \\
\text { Prediction }\end{array}$ \\
\hline $\mathrm{SRH}$, & Storm relative helicity \\
\hline SWEAT, & Severe weather threat \\
\hline TT, & Total totals \\
\hline VGP, & Vorticity Generator Parameter \\
\hline WBZ, & Height of the wet-bulb zero \\
\hline ZAPE, & Zonal available potential energy \\
\hline ZKE, & Zonal kinetic energy \\
\hline
\end{tabular}

Acknowledgements. This study was undertaken within the framework of project FLASH which is funded by the European Union (Sixth Framework Programme, Contract No. 036852). The authors wish to express their gratitude to two anonymous reviewers and to Yoav Yair of the Open University of Israel, whose comments and suggestions have led to the improvement of this paper.

Edited by: F. Tymvios

Reviewed by: Y. Yair and two other anonymous referees

\section{References}

Carlson, T. N.: Mid-latitude weather systems, Harper Collins Academic, London, UK, 507 pp., 1991.

El-Fandy, M. G.: Barometric Lows of Cyprus, Q. J. Roy. Met. Soc., 72, 291-306, 1946.

Jacobeit, J.: Variations of trough position and precipitation patterns in the Mediterranean area, J. Climatol., 7, 453-476, 1987.

Jacovides, C. P. and Yonetani, T.: An evaluation of stability indices for thunderstorm prediction in greater Cyprus, Weather Forecast., 5, 559-569, 1990.

Kallos, G. and Metaxas, D. A.: Synoptic processes for the formation of Cyprus lows, Riv. Meteorol. Aeronau., 40(2-3), 121-138, 1980.

Lynn, B. and Yair, Y.: Prediction of lightning flash density with the WRF model, Adv. Geosci., 23, 11-16, 2010, http://www.adv-geosci.net/23/11/2010/.

Maheras, P., Flocas, H., Patrikas, I., and Anagnostopoulou, C.: A 40 year objective climatology of surface cyclones in the Mediterranean region: Spatial and temporal distribution, Int. J. Climatol., 21, 109-130, 2001.

Maheras, P., Flocas, H. A., Anagnostopoulou, C., and Patrikas, I.: On the vertical structure of composite surface cyclones in the Mediterranean region, Theor. Appl. Climatol., 71, 199-217, 2002.

Michaelides, S. C.: Limited area energetics of Genoa cyclogenesis, Mon. Weather Rev., 115, 13-26, 1987.

Michaelides, S. C.: A spatial and temporal energetics analysis of a baroclinic disturbance in the Mediterranean, Mon. Wea. Rev., 120, 1224-1243, 1992.

Michaelides, S., Nicolaides, K., and Karacostas, T.: Statistical characteristics of the cold season depressions over the area of Cyprus, Meteorologickýèasopis 7, 61-66, 2004.

Michaelides, S. C., Prezerakos, N. G., and Flocas, A. A.: QuasiLagrangian energetics of an intense Mediterranean cyclone, Q. J. Roy. Met. Soc., 125, 139-168, 1999.

Michalopoulou, H. and Jacovides, C. P.: Instability indices for the Cyprus area, Meterol. Atmos. Physics, 37, 153-157, 1987.

National Weather Service: http://www.crh.noaa.gov/lmk/soo/docu/ indices.php, last access: 14 June 2009.

Nicolaides, K.: Synoptic and dynamic study of the depression cases affected the wider area of Cyprus during cold months, $\mathrm{PhD}$ thesis, Aristotelian University, 278 pp., Thessaloniki, Greece, 2005 (in Greek).

Nicolaides, K., Michaelides, S., and Karacostas, T.: Spatial distribution of some dynamic parameters during the evolution of selected depressions over the area of Cyprus, Int. J. Climatol., 24, 1829-1844, 2004. 
Nicolaides, K., Savvidou, K., Orphanou, A., Michaelides, S., Constantinides, P., Papachristodoulou, C., and Savvides, M.: An investigation of a baroclinic depression that affected the area of Cyprus, Adv. Geosci., 16, 1-8, 2008, http://www.adv-geosci.net/16/1/2008/.

Radinovic, D.: Mediterranean cyclones and their influence on the weather and climate, program on short and medium range weather prediction research, PSMP, W.M.O. Sofia, 1987.

Savvidou, K., Orphanou, A., Charalambous, D., Lingis, P. and Michaelides, S.: A statistical analysis of sounding derived indices and parameters for extreme and non-extreme thunderstorm events over Cyprus, Adv. Geosci., 23, 79-85, 2010

Shay-El, Y. and Alpert, P.: A diagnostic study of winter diabatic heating in the Mediterranean in relation to cyclones, Q. J. Roy. Meteorol. Soc., 117, 715-747, 1991.

Stein, U. and Alpert, P.: Factor separation in numerical simulations, J. Atmos. Sci., 50, 2107-2115, 1993.
Tafferner, A. and Egger, J.: Test of theories of lee cyclogenesis: ALPEX cases, J. Atmos. Sci., 47, 2417-2428, 1990.

Trigo, I. F., Davies, T. D., and Bigg, G. R.: Objective climatology of cyclones in the Mediterranean region, J. Climate, 12, 16851696, 1999.

Tudurí, E. and Ramis, C.: The Environments of Significant Convective Events in the Western Mediterranean, Weather Forecast., 12, 294-306, 1997.

Ziv, B., Saaroni, H., Yair, Y., Ganot, M., Baharad, A., and Isaschari, D.: Atmospheric factors governing winter thunderstorms in the coastal region of the eastern Mediterranean, Theor. Appl. Climatol., 95, 301-310, 2009.

Ziv, B., Saaroni, H., Romem, M., Heifetz, E., Harnik, N., and Baharad, A.: Analysis of conveyor belts in winter Mediterranean cyclones, Theor. Appl. Climatol., 99, 441-455, 2010. 